\title{
Карбонатиты, фениты и карбонатно-щелочные метасоматиты Западного Прибайкалья: минералого-геохимическое сопоставление
}

\author{
Савельева В.Б., Базарова Е.П. \\ Институт земной коры СО РАН, Иркутск, vsavel@crust.irk.ru
}

\begin{abstract}
Аннотация. Проведено минералого-геохимическое сопоставление доломит-анкеритовых карбонатитов, фенитов и карбонатно-щелочных метасоматитов Западного Прибайкалья. По петрографическим признакам отличить карбонатно-щелочные метасоматиты от фенитов трудно. Более показательны присутствие акцессорных минералов $\mathrm{Nb}$ в фенитах и U-содержащих минералов в карбонатно-щелочных метасоматитах, а также особенности редкоэлементного состава пород.

Ключевые слова: Западное Прибайкалье, карбонатиты, фениты, карбонатно-щелочные метасоматиты, альбитизация, рибекитизация, доломитизация.
\end{abstract}

\section{Carbonatites, fenites and carbonate-alkaline metasomatites of the Western Baikal region: mineralogical and geochemical comparison}

\author{
Savelyeva V.B., Bazarova E.P. \\ Institute of the Earth's Crust, SB RAS, Irkutsk, vsavel@crust.irk.ru
}

\begin{abstract}
The mineralogical and geochemical comparison of dolomite-ankerite carbonatites, fenites and carbonate-alkaline metasomatites of the Western Baikal region was carried out. According to petrographic features, it is difficult to distinguish carbonate-alkaline metasomatites from fenites. The presence of accessory $\mathrm{Nb}$ minerals in fenites and U-containing minerals in carbonate-alkaline metasomatites, as well as the features of rare-element composition of rocks, are more indicative.
\end{abstract}

Key words: Western Baikal Area, carbonatites, fenites, carbonate-alkaline metasomatites, albitization, riebeckitization, dolomitization.

\section{Введение}

Карбонатиты являются одними из наиболее интересных с точки зрения геохимии и генезиса производными мантийного магматизма, имеющими важное экономическое значение, поскольку с ними связаны крупные ресурсы $\mathrm{Ta}, \mathrm{Nb}, \mathrm{REE}, \mathrm{Fe}, \mathrm{Ti}, \mathrm{P}, \mathrm{Cu}$ и др. Становление карбонатитов обычно сопровождается фенитизацией - высокотемпературным щелочным метасоматозом. Иногда щелочные метасоматиты содержат редкометалльную $(\mathrm{Nb}, \mathrm{Zr}, R E E)$ минерализацию.

В отличие от фенитов, щелочно-карбонатные метасоматиты является поисковым признаком для гидротермальных месторождений урана. При этом остается много вопросов в отношении состава минерализирующих флюидов, их источников, физико-химических условий отложения руды и др. Высказывается мнение о генетической связи месторождений с карбонатитовым и/или щелочным магматизмом (Wilde, 2013).

В пределах Байкальского выступа на юге Сибирского кратона известны проявления как карбонатитов, сопровождающихся ореолами фенитизации во вмещающих породах, так и проявления карбонатно-щелочного метасоматоза, что позволяет провести их сопоставление.

\section{Геологическая позиция}

Карбонатиты и карбонатно-щелочные метасоматиты локализованы в южной части Байкальского краевого выступа Сибирского кратона и приурочены к зоне сочленения кратона и СаяноБайкальской складчатой области. Район сложен метаморфизованными терригенно-вулканогенными образованиями $\mathrm{PR}_{1}$, син-и постколлизионными гранитами (возраст постколлизионных гранитов 1.86 млрд. лет (Донская и др., 2003)) и прорывающими их дайками габбро-диабазов с возрастом $787 \pm 21$ млн. лет (Gladkochub et al., 2010). 
Таблица 1. Акцессорные минералы карбонатитов и метасоматитов.

Table 1. Accessory minerals of carbonatites and metasomatites.

\begin{tabular}{|c|c|c|c|c|}
\hline Минералы & 1 & 2 & 3 & 4 \\
\hline Магнетит $\mathrm{Fe}_{3} \mathrm{O}_{4}$ & + & + & + & + \\
\hline Ильменит $\mathrm{FeTiO}_{3}$ & + & + & + & + \\
\hline Экандрюсит $\left(\mathrm{Zn}, \mathrm{Fe}^{2+}, \mathrm{Mn}^{2+}\right) \mathrm{TiO}_{3}$ & + & & & \\
\hline Гематит $\mathrm{Fe}_{2} \mathrm{O}_{3}$ & & + & & \\
\hline Рутил $\mathrm{TiO}_{2}$ & + & + & + & + \\
\hline Пирохлор $(\mathrm{Ca}, \mathrm{Na})_{2} \mathrm{Nb}_{2} \mathrm{O}_{6}(\mathrm{OH}, \mathrm{F})$ & + & & & \\
\hline Ферроколумбит $\mathrm{Fe}^{2+} \mathrm{Nb}_{2} \mathrm{O}_{6}$ & & + & & \\
\hline Эвксенит-(Y) (Y, Ca, Ce, U,Th)(Nb, Ta, Ti) ${ }_{2} \mathrm{O}_{6}$ & + & & & \\
\hline Эшинит-(Ce) $(\mathrm{Ce}, \mathrm{Ca}, \mathrm{Fe}, \mathrm{Th})(\mathrm{Ti}, \mathrm{Nb})_{2}(\mathrm{O}, \mathrm{OH})_{6}$ & & & + & \\
\hline Кричтонит (группа) & & + & & + \\
\hline Циркон $\mathrm{ZrSiO}_{4}$ & + & + & + & + \\
\hline Торит $\mathrm{ThSiO}_{4}$ & + & & + & + \\
\hline Церит-(Ce) $(\mathrm{Ce}, \mathrm{Ca})_{9}\left(\mathrm{Mg}, \mathrm{Fe}^{2+}\right) \mathrm{Si}_{7}(\mathrm{O}, \mathrm{OH}, \mathrm{F})_{28}$ & & & + & + \\
\hline Таленит-(Y)? $\mathrm{Y}_{3} \mathrm{Si}_{3} \mathrm{O}_{10}(\mathrm{~F}, \mathrm{OH})$ & & + & & \\
\hline Алланит- $(\mathrm{Ce})(\mathrm{Ce}, \mathrm{Ca}, \mathrm{Y})_{2}\left(\mathrm{Al}, \mathrm{Fe}^{3+}\right)_{3}\left(\mathrm{SiO}_{4}\right)_{3}(\mathrm{OH})$ & + & & + & + \\
\hline Титанит $\mathrm{CaTiSiO}_{5}$ & & & + & + \\
\hline $\mathrm{Sr}$-эпидот $(\mathrm{Ca}, \mathrm{Sr})_{2}\left(\mathrm{Al}, \mathrm{Fe}^{3+}\right)_{3}\left(\mathrm{SiO}_{4}\right)_{3}(\mathrm{OH})$ & & & & + \\
\hline Фторапатит $\mathrm{Ca}_{5}\left(\mathrm{PO}_{4}\right)_{3} \mathrm{~F}$ & + & + & + & + \\
\hline Монацит-(Ce) $(\mathrm{Ce}, \mathrm{La}, \mathrm{Nd}, \mathrm{Th}) \mathrm{PO}_{4}$ & + & + & + & + \\
\hline Ксенотим-(Y) $\mathrm{YPO}_{4}$ & + & + & & + \\
\hline Бастнезит-(Ce) $(\mathrm{Ce}, \mathrm{La}) \mathrm{CO}_{3} \mathrm{~F}$ & + & & & + \\
\hline Бурбанкит $(\mathrm{Na}, \mathrm{Ca})_{3}(\mathrm{Sr}, \mathrm{Ba}, \mathrm{Ce})\left(\mathrm{CO}_{3}\right)_{5}$ & + & & & \\
\hline Барит $\mathrm{BaSO}_{4}$ & + & + & + & + \\
\hline Пирит $\mathrm{FeS}_{2}$ & + & + & + & + \\
\hline Халькопирит $\mathrm{CuFeS}_{2}$ & + & & + & + \\
\hline Галенит PbS & + & & & + \\
\hline Сфалерит ZnS & + & & & \\
\hline Сульфиды Cu (и Вi)* & & & & + \\
\hline Смитсонит $\mathrm{ZnCO}_{3}$ & + & + & & \\
\hline Церуссит $\mathrm{PbCO}_{3}$ & + & & & \\
\hline Настуран ${ }^{* *}$ & & & & + \\
\hline
\end{tabular}

Примечание. 1-3 - Онгуренский комплекс: 1 - доломит-анкеритовые карбонатиты, 2 - микроклиновые метасоматиты, 3- магнезиорибекитовые метасоматиты; 4 - карбонатно-щелочные метасоматиты (в целом). * - борнит $\mathrm{Cu}_{5} \mathrm{FeS}_{4}$, ярроуит $\mathrm{Cu}_{9} \mathrm{~S}_{8}$, ковеллин $\mathrm{CuS}$, халькокит $\mathrm{Cu}_{2} \mathrm{~S}$, виттихенит $\mathrm{Cu}_{3} \mathrm{BiS}_{3}$; ** - по данным Coсновской экспедиции.

Note: 1-3 - Ongurensky complex: 1 - dolomite-ankerite carbonatites, 2 - microcline metasomatites, 3- magnesioribekite metasomatites; 4 - carbonate-alkaline metasomatites (in general). * - bornite $\mathrm{Cu}_{5} \mathrm{FeS}_{4}$, yarrowite $\mathrm{Cu}_{9} \mathrm{~S}_{8}$, and covellite $\mathrm{CuS}$, chalcocite $\mathrm{Cu}_{2} \mathrm{~S}$, wittichenite $\mathrm{Cu}_{3} \mathrm{BiS}_{3} ; * *$ - according to Sosnovskaya expedition.

Онгуренский карбонатитовый комплекс (около 1.0 млрд. лет) (Савельева и др., 2016) включает более 20 даек и жил карбонатитов мощностью от 1-3 см до 1.5 м. Это доломит-анкеритовые карбонатиты, в меньшей мере кальцитовые карбонатиты, силикокарбонатиты и редкие дайки пикритов и фоскоритов. Внедрению карбонатитов предшествовали калиевый метасоматоз и гематитизация, проявленные на участках катаклаза и брекчирования в сотни метров и шириной до 100 м. Рибекитизация развита на участке протяженностью около 10 км, шириной до 2 км. Локально проявлены доломитизация, флогопитизация, апатитизация и др. 
Район проявления карбонатно-щелочных метасоматитов с бедной U минерализацией (гидратированный настуран, по данным Сосновской экспедиции) сложен биотит-хлоритовыми сланцами, метаэффузивами основного и среднего состава, метапесчаниками, которые прорываются аляскитовыми гранитами. В зоне шириной около 50-70 м натриевый метасоматоз и карбонатизация наложились на катаклазированные и милонитизированные метаэффузивы, аляскиты и дайку лампрофира.

\section{Петрография}

Карбонатиты представлены мелкозернистыми, иногда порфировидными породами, на 70-90 \% состоящими из карбоната. В кальцитовых карбонатитах кроме кальцита присутствуют флогопит, в небольшом количестве доломит, апатит, титаномагнетит и др. В доломит-анкеритовых карбонатитах карбонат принадлежит к изоморфному ряду доломит $\mathrm{CaMg}\left(\mathrm{CO}_{3}\right)_{2}-$ анкерит $\mathrm{Ca}(\mathrm{Mg}, \mathrm{Fe})\left(\mathrm{CO}_{3}\right)_{2}$. Породы содержат также кальцит, кварц, микроклин, альбит, флогопит, магнезиорибекит, эгирин, магнетит, апатит и др. (табл. 1).

Калиевая фенитизация выражается в появлении в гнейсах и гранитах каемок и прожилков лейстовидного калиевого полевого шпат; исчезновении биотита, который замещается микроклином с вростками магнетита/гематита и рутила. Вблизи карбонатитов в метасоматитах наблюдаются прожилки доломита в ассоциации с флогопитом.

Натриевая фенитизация начинается с раскисления плагиоклаза в гнейсах и гранитах и появлении мелких зерен актинолита; затем возникают каймы щелочного амфибола ( \pm редкий пироксен), замещающего кварц, полевые шпаты и слюду. Породы тыловой зоны образуют прослои мощностью 2-5 см, на 85-90 \% сложенные амфиболом (土 альбит, кальцит, титанит).

\begin{tabular}{|l|l|}
\hline Колонка К-фенитизации: & Колонка Na-фенитизации: \\
\hline Кв+Пл+Би & Кв+Пл+Би \\
\hline Микр+Флог (Кв, Пл) & Аб+Акт+Ка (Кв, Би) \\
\hline Микр (+Мгт/Гем) & Аб+Риб \pm Ка (Кв) \\
\hline & Риб ( \pm Аб, Ка) \\
\hline
\end{tabular}

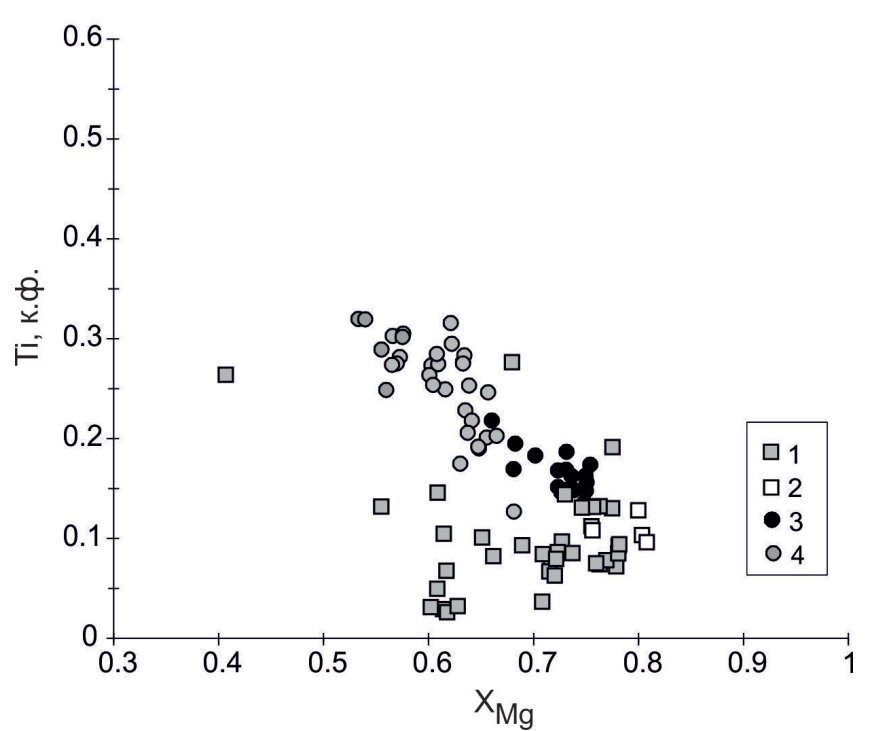

Рис. 1. Соотношение $\mathrm{Ti}-\mathrm{XMg}$, к.ф., в слюдах.

Слюды: 1, 2 - из фенитов: 1 - калиевых, 2 - натриевых тыловой зоны, 3, 4 - из карбонатно-щелочных метасоматитов: 3 - альбит-рибекитовых, 4 - доломит-биотитовых.

Fig. 1. Ti $-\mathrm{XMg}$, apfu, diagram for micas.

Mica: 1, 2 - fenite: 1 - potassium, 2 - sodium; 3, 4- carbonate-alkaline metasomatites: 3 - albite-riebeckite, 4 - dolomite-biotite.
На участке карбонатно-щелочного метасоматоза в аляскитах наблюдаются альбитизация, сопровождающаяся образованием рибекита и отложением кальцита, и более поздняя доломитизация. Альбитрибекитовые метасоматиты на 75-80 \% сложены шахматным альбитом, среди которого сохраняются кварц и плагиоклаз ранней генерации. Темноцветные минералы представлены мелким биотитом и щелочным амфиболом. Особенно интенсивно амфиболизация проявлена на контакте с дайкой лампрофира. В доломитизированных гранитах альбитизация проявлена неравномерно, микроклин постоянно присутствует; с доломитом ассоциируются биотит и магнетит. В милонитизированных гранитах доломит слагает послойные мелкозернистые прожилки мощностью до 1.5 см с оторочками биотита. Наиболее поздние образования представлены кварцевыми и кварц-карбонатными ( \pm рибекит-асбест, альбит, флогопит, хлорит, флогопит) жилами мощностью до 0.2 м. 
Колонки карбонатно-щелочного метасоматоза в аляскитовых гранитах:

\begin{tabular}{|c|c|}
\hline Стадия $\mathrm{Na}-\mathrm{Ca}-\mathrm{CO}_{2}$ метасоматоза: & Стадия K-Ca-Mg-CO ${ }_{2}$ метасоматоза: \\
\hline Кв+Микр+Пл кисл & Кв+Микр+ПЛ \\
\hline Аб+Риб+Ка+Кв + Флог & Дол+Би+Микр (Кв, Аб) \\
\hline Аб+Риб+Ка & Дол+Би \\
\hline
\end{tabular}

\section{Минералого-геохимическое сопоставление}

В доломитовых карбонатитах состав карбоната варьирует от чистого доломита до железистого доломита: количество (мас. \%) $\mathrm{FeO}$ до 14 (до 40 мол. \% $\left.\mathrm{CaFe}\left(\mathrm{CO}_{3}\right)_{2}\right), \mathrm{SrO}$ 0.4-0.7, $\mathrm{MnO}$ до 1.4. Доломит из калиевых фенитов имеет сходный состав (мас. \%): $\mathrm{FeO}=0.5-14.5$ (1.5-42 мол. \% $\left.\mathrm{CaFe}\left(\mathrm{CO}_{3}\right)_{2}\right)$; $\mathrm{MnO}$ 0.4-1.9. В карбонатно-щелочных метасоматитах доломит из метасоматических прожилков содержит (мас. \%) 8.7-14.0 FeO (22-38 мол. \% $\left.\mathrm{CaFe}\left(\mathrm{CO}_{3}\right)_{2}\right)$, до $1.1 \mathrm{MnO}$. Кальцит содержит 0.25-0.84 мас. \% SrO.

Слюда в доломит-анкеритовых карбонатитах представлена зональным флогопитом $\left(\mathrm{X}_{\mathrm{Mg}}=0.83-0.91\right.$ в центре и 0.58-0.64 на краю зерен). В Na-фенитах слюда также представлена флогопитом ( $\left.\mathrm{X}_{\mathrm{Mg}}=0.76-0.81\right)$, а в К-фенитах - за редким исключением флогопитом и магнезиальным биотитом $\left(\mathrm{X}_{\mathrm{Mg}}=0.61-0.78\right)$. В карбонатно-щелочных метасоматитах слюда, в целом, более титанистая, чем в фенитах; $\mathrm{X}_{\mathrm{Mg}}=0.66-0.75$ в альбит-рибекитовых метасоматитах и снижается до 0.53-0.56 в доломитовых прожилках (рис. 1).

Амфибол в карбонатитах представлен магнезиорибекитом и значительно более редким магнезиарфведсонитом. Новообразованные амфиболы в Na-фенитах представлены актинолитом, винчитом и магнезиорибекитом. В карбонатно-щелочных метасоматитах в основном присутствует магнезиорибекит, но отмечаются также рибекит и винчит (рис. 2).

Карбонатиты, фениты и карбонатно-щелочные метасоматиты, содержат, в основном, сходный набор акцессорных минералов (табл. 1). Однако, для карбонатитов и фенитов характерны тантало-и титанониобаты, которые отсутствуют в карбонатно-щелочных метасоматитах. Кроме того, содержание $\mathrm{Nb}_{2} \mathrm{O}_{5}$ (мас. \%) в минералах из фенитов выше, чем в тех же минералах из карбонатно-щелочных метасоматитов: ильменит - до 2 и ниже предела обнаружения, соответственно, рутил - до 7 и 2.4 , титанит - до 1.8 и до 0.7. В то же время, минералы из карбонатно-щелочных метасоматитов содер-

a

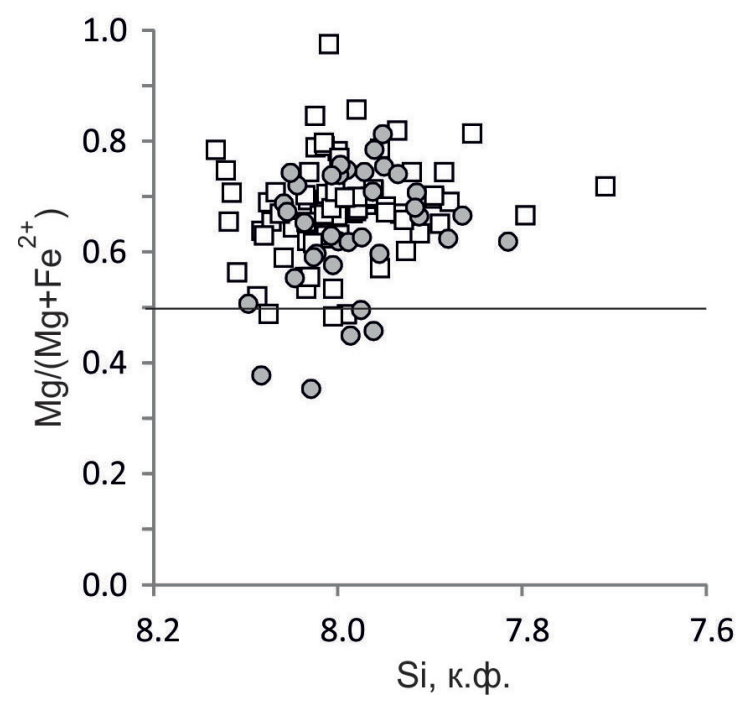

6

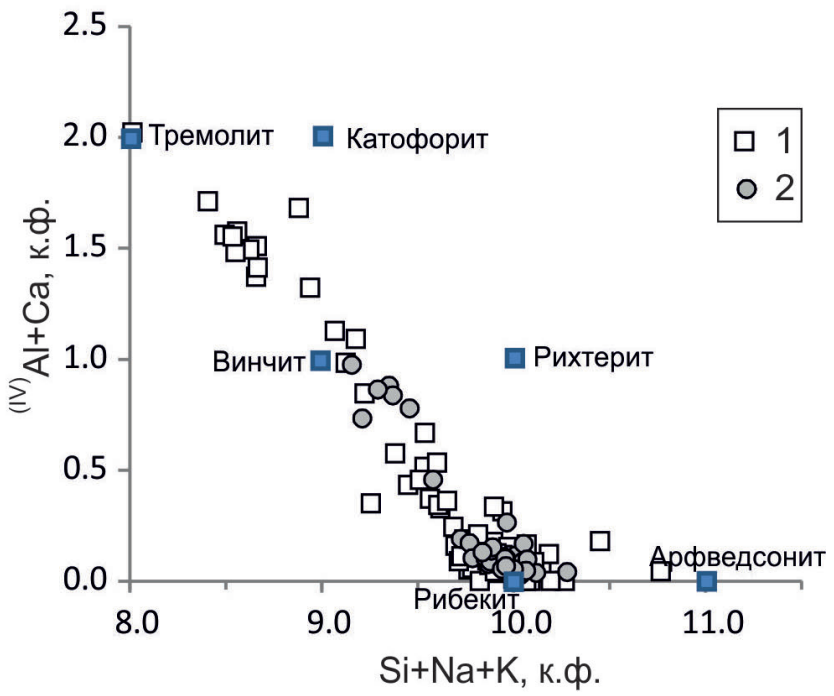

Рис. 2. Соотношения $\mathrm{Mg} /\left(\mathrm{Mg}^{2} \mathrm{Fe}^{2+}\right)-\mathrm{Si}\left(\right.$ a) и ( $\left.{ }^{(\mathrm{IV})} \mathrm{Al}+\mathrm{Ca}\right)-(\mathrm{Si}+\mathrm{Na}+\mathrm{K})$ (б), к.ф., в амфиболах. Амфиболы: 1 - из Na-фенитов; 2 - из карбонатно-щелочных метасоматитов.

Fig. 2. $\mathrm{Mg} /\left(\mathrm{Mg}+\mathrm{Fe}^{2+}\right)-\mathrm{Si}(\mathrm{a})$ and $\left({ }^{(\mathrm{IV})} \mathrm{Al}+\mathrm{Ca}\right)-(\mathrm{Si}+\mathrm{Na}+\mathrm{K})(\mathrm{b})$, apfu, diagrams for amphiboles. Amphiboles: 1 - from Na-phenites; 2 - from carbonate-alkaline metasomatites. 
жат повышенные количества $\mathrm{UO}_{2}$ (мас. \%): циркон до 1.1, торит 1.4-4.6, минералы группы кричтонита 2.6-8.9. Для карбонатно-щелочных метасоматитов характерно также большее разнообразие сульфидов.

Доломитовые прожилки в карбонатно-щелочных метасоматитах сходны по содержаниям петрогенных компонентов с доломит-анкеритовыми карбонатитами (табл. 2), однако в прожилках ниже содержания $L n_{\mathrm{Ce}}$, Sr, P, Th и выше U; им присуще слабо дифференцированное распределение лантаноидов $(\mathrm{La} / \mathrm{Yb}=5)$, наличие $\mathrm{Eu}$ минимума $\left(\mathrm{Eu} / \mathrm{Eu}^{*}=0.69\right)$, «пики» $\mathrm{U}$ и $\mathrm{Pb}$ и отсутствие минимума Zr-Hf на спектре редких элементов, нормированных относительно содержаний в примитивной мантии (рис. 3).

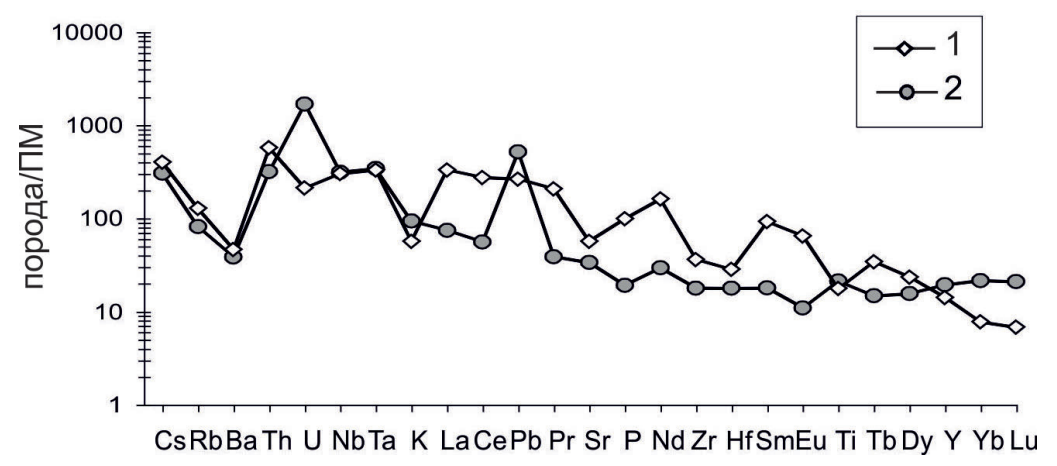

Рис. 3. Спайдерграммы доломит-анкеритового карбонатита (1) и доломитового прожилка (2).

Fig. 3. Spidergrams of dolomite-ankerite carbonatite (1) and a dolomitic veinlet (2).

Таблица 2. Химический состав доломит-анкеритовых карбонатитов (Carb) и метасоматических доломитовых прожилков (Met).

Table 2. The chemical composition of dolomite-ankerite carbonatites (Carb) and metasomatic dolomite veins (Met).

\begin{tabular}{|c|c|c|c|c|c|c|c|c|c|c|c|}
\hline & $\mathrm{SiO}_{2}$ & $\mathrm{TiO}_{2}$ & $\mathrm{Al}_{2} \mathrm{O}_{3}$ & $\mathrm{FeO}$ & $\mathrm{MnO}$ & $\mathrm{MgO}$ & $\mathrm{CaO}$ & $\mathrm{Na}_{2} \mathrm{O}$ & $\mathrm{K}_{2} \mathrm{O}$ & $\mathrm{P}_{2} \mathrm{O}_{5}$ & $\mathrm{CO}_{2}$ \\
\hline Carb & 15.81 & 3.85 & 2.92 & 11.73 & 0.35 & 10.91 & 21.56 & 0.26 & 1.67 & 2.07 & 26.94 \\
\hline Met & 20.19 & 4.23 & 4.01 & 10.78 & 0.40 & 9.49 & 18.90 & 0.18 & 2.53 & 0.24 & 26.07 \\
\hline & $\mathrm{Sr}$ & $\mathrm{Y}$ & $\mathrm{Zr}$ & $\mathrm{Nb}$ & $\mathrm{Ba}$ & $\mathrm{La}$ & $\mathrm{Ce}$ & $\mathrm{Ta}$ & $\mathrm{Pb}$ & $\mathrm{Th}$ & $\mathrm{U}$ \\
\hline Carb & 1143 & 62 & 385 & 201 & 310 & 217 & 465 & 12 & 21 & 46 & 4.3 \\
\hline Met & 635 & 58 & 145 & 165 & 235 & 36 & 90 & 12 & 38 & 25 & 32 \\
\hline
\end{tabular}

\section{Выводы}

Только по петрографическим признакам отличить ураноносные карбонатно-щелочные метасоматиты от фенитов трудно. Карбонат и щелочной амфибол в этих породах имеют сходный химический состав. Более показательны особенности химического состава акцессорных минералов и присутствие типоморфных минералов $\mathrm{Nb}$ в фенитах и U-содержащих минералов в карбонатнощелочных метасоматитах. Показательно также сопоставление мультиэлементных спектров, позволяющее предполагать отсутствии генетической связи карбонатно-щелочных метасоматитов с карбонатитами.

Работа выполнена в рамках темы НИР №0346-2019-0003 при частичной поддержке РФФИ (грант 17-05-00819).

\section{Литература}

1. Донская Т.В., Бибикова Е.В., Мазукабзов А.М., Козаков И.К., Гладкочуб Д.П., Кирнозова Т.И., Плоткина Ю.В., Резницкий Л.З. Приморский комплекс гранитоидов Западного Прибайкалья: геохронология, геодинамическая типизация // Геология и геофизика. 2003. Т. 44. № 10. С. 1006-1016.

2. Савельева В.Б., Демонтерова Е.И., Данилова Ю.В., Базарова Е.П., Иванов А.В., Каменецкий В.С. Новый карбонатитовый комплекс в Западном Прибайкалье (юг Сибирского кратона): минеральный состав, возраст, геохимия и петрогенезис // Петрология. 2016. Т. 24. № 3. С. 292-324.

3. Gladkochub D.P., Pisarevsky S.A., Donskaya T.V., Ernst R.E., Wingate M.T.D., Söderlund U., Mazukabzov A.M., Sklyarov E.V., Hamilton M.A., Hanes J.A.. Proterozoic mafic magmatism in Siberian craton: An overview and implications for paleocontinental reconstruction // Precambrian Research. 2010. V. 183. P. 660-668.

4. Wilde A. Towards a model for albitite-type uranium // Minerals. 2013. V. 3. P. 36-48. 